\title{
CHARACTERIZATION OF THE USE OF BIM IN THE BRAZILIAN STATES RIO GRANDE DO NORTE AND PARAIIBA
}

\author{
Maria L. A. E. Borges ${ }^{1}$, Reymard S. S. de Melo ${ }^{2}$, Josyanne P. Giesta ${ }^{3}$, Danilo G. V. Santos ${ }^{4}$
}

\begin{abstract}
Several studies have sought to measure Building Information Modeling utilization on a national scale in many countries, including Brazil. Although it's a diagnostic parameter, the results of BIM macro adoption analysis become inconsistent when compared with the reality of smaller regions, especially in a continental country such as Brazil. Its implementation occurs partially and not homogeneously in Brazilian Architecture, Engineering and Construction companies within the country territory. In a country as vast and marked by inequalities as Brazil, research that analyzes the use of the platform nationally becomes generalist, making its results discrepant when compared with the individual reality of some states. Thus, there is a need to take a regional analysis, trying to avoid generalizations found in previous research. There is little research that does this on a regional scale. This paper aims to evaluate parameters on BIM implementation in Rio Grande do Norte (RN) and Paraíba (PB), two Brazilian northeastern states, a region not covered in previous research. A structured online questionnaire was answered by these states' construction companies to characterize the use of BIM. Results show that RN is a little bit in advantage on BIM usage when compared to $\mathrm{PB}$. The major contribution of this work is the characterization of the BIM use in the states of RN and $\mathrm{PB}$. Understanding local particularities can drive overcoming difficulties that prevent the spread of technology.
\end{abstract}

Keywords: BIM, BIM use, Characterization, Questionnaire.

\section{INTRODUCTION}

Building Information Modeling (BIM) is defined as a set of policies, processes and technologies that lead to the establishment of a methodology for the generation, updating and maintenance, in digital format, of all information relevant to the life cycle of an enterprise (Succar 2009).

Despite many barriers and difficulties, some countries have already started migrating to BIM more than a decade ago and are therefore at a high level of maturity. In a survey of ten countries from North America, South America, Europe, Asia and Oceania, the results show that BIM adoption is considerably accelerating, driven mainly by large contractors and government agencies that want the benefits of faster, safer, more reliable and cost-effective project delivery (Jones and Bernstein 2014).

In the United States, BIM utilization among contractors increased from $28 \%$ to $71 \%$ between 2007 and 2012. Meanwhile, the same research shows that BIM projects in Brazil

PhD candidate, University of Campinas, Campinas, Brazil, mluizabath@gmail.com

Assistant professor, Federal University of Bahia, Salvador, Brazil, reymardsavio@gmail.com

Assistant professor, Federal Institute of Rio Grande do Norte, Natal, Brazil, josyannegiesta@yahoo.com.br

4 Graduate student, Federal University of Rio Grande do Norte, Natal, Brazil, danilo.gvs@gmail.com 
are still incipient. Compared to the other countries included in the study, BIM users in Brazil are much newer and have a low engagement rate. This index is measured based on BIM usage time, experience level and implementation level (Jones and Bernstein 2014).

Other studies sought to measure the adoption of BIM in Brazilian territory. On a national scale, the research carried out with architects and engineers on the use of BIM in Brazil stands out. The results showed that most of the 588 respondents still did not work with this technology at the time. The research is quite generic, aiming only to identify who uses it and for which purpose (Pini 2013).

Another more recent research has assessed the maturity level of BIM adoption in several countries, including Brazil. A study evaluated and compared the macro diffusion of BIM, which means, on a nation scale, across several countries. Data were obtained by applying an online questionnaire, answered by 99 experts from 21 countries. The results of this research may be considered insufficient to accurately portray the Brazilian reality. While for the UK 16 participants were selected, for a vastly larger country like Brazil only 4 participants were invited. For the evaluation of macro adoption, participants assigned five-level indices to eight requirements. From a total of 20 points, Brazil obtained an average of 5.4. By contrast, the highest-matched BIM nation in the world, the United Kingdom, scored 17.7 points (Kassem et al. 2015).

In Brazil, further mass adoption of BIM is expected in the coming years, as was enacted, in May of 2018, the National Dissemination Strategy of Building Information Modeling. Also called the BIM BR Strategy, its main objective is to spread BIM in the country. In addition, there are government initiatives by some states such as Mato Grosso, Santa Catarina, Paraná, Rio de Janeiro and Rio Grande do Sul. Therefore, it is presumed that the BIM adoption is more developed in some regions of the country than in others, and that the problems faced also vary from one location to another. This is how in a country as vast and marked by inequalities as Brazil, made up of twenty seven states, distributed in five regions, research that analyzes the use of the platform nationally becomes generalist, making its results discrepant when compared with the individual reality of some states. Therefore, there is a need for characterization of each regional BIM uses.

Only a few researches have done this on a regional scale. A study analyzed the adoption of BIM in the Distrito Federal state, through an online questionnaire answered by sixteen of the leading construction companies operating in the residential and commercial real estate market in the state. In this study, questions were asked to ascertain the interviewees' knowledge about the BIM platform, its common uses, results obtained from its application and main difficulties during its implementation or reasons for not doing so. Finally, professionals are questioned about their prospects for using technology over the next five years. Research results indicate that the use of BIM in the Distrito Federal is still small and superficial. The barriers indicated by respondents are complex and mostly involve training and capacity building, a process that happens slowly and has a high cost (Carmona and Carvalho 2017).

Another research also applied an online questionnaire with engineers, architects and other professionals related to the management of construction companies and engineering and architecture offices in the state of Santa Catarina. The objective was to evaluate how the implementation of BIM in the state is being done, after the determination made by the State Government in 2014, requiring the use of BIM for all public works. The questions addressed analyze the knowledge of professionals about the platform and how they are using it. More than 90 companies from Santa Catarina 
participated in the research and allowed to better understand how the process of implementation of BIM in the state is. It was noted that most companies were preparing to meet the required standards (Steiner 2016).

Understanding local particularities can drive overcoming difficulties that prevent the spread of technology. The best path for implementation in one location may not be the other because it faces different obstacles. Precisely because it understands that these differences exist, even with the BIM BR Strategy launched, the state of Rio de Janeiro instituted in October 2018 the BIM RJ Strategy, in accordance with Decree No. 9,377. The tendency is for this to happen to other states, as the Brazilian Chamber of BIM (CBIM, by its acronym in Portuguese) itself has split into the Brazilian states. Therefore, the characterization of the regional adoption of BIM becomes crucial.

Given this, by characterizing the use of BIM in the states of Rio Grande do Norte and Paraíba, this paper aims to bring parameters of the adoption of BIM in two neighboring states of the Northeast, not yet contemplated in previous research. In addition to filling this theoretical gap, this study differs from the previous ones by addressing in its questionnaire the temporal particularity of economic recession that Brazil has experienced in recent years.

\section{INCENTIVES FOR BIM ADOPTION IN BRAZIL}

Gradually BIM is no longer a trend and becomes a reality for the construction indus-try. Its adoption is growing year by year and the expectation is that most companies will eventually adopt the technology, such as did the transition from drawing boards to Computer-Aided Design (CAD) in the early 1990's and 2000's. Enterprises are likely to be gradually disqualified in the labor market if such adoption occurs late or, in some cases, it doesn't happen (Eastman et al. 2008).

Greater gains are identified for the adoption of BIM when it is combined with actions by government agencies in the definition of mandates indicating the guidelines and standardization required in the use of the methodology (Smith 2014). This movement is evidenced by the growing intensity of discussions around BIM and the accelerated availability of Notable BIM Publications (NBP's). NBP's are publicly available indus-try documents incorporating guidelines, protocols, and requirements focused on BIM products and workflows. These publications are the product of various agencies, industry associations, communities of practice, and research institutions designed to facilitate BIM adoption and achieve BIM's added value potential.

Therefore, as a way of encouraging its implementation, several efforts have been made by companies and governments, from the elaboration of guides to the requirements of rules and exclusive bidding for BIM projects. Countries such as the United States, the United Kingdom, Finland, Singapore, Norway, and Hong Kong are pio-neers in guideline publications that present strategies and approaches from govern-ment initiatives. Such standardizations help ensure the most appropriate targeting of efforts for lasting investments in BIM deployments in the enterprise market (Farias et al. 2016).

In Brazil, there are two major NBP's, the "AsBEA Guide: Best Practices in BIM" (2015) created by the Brazilian Association of Architecture Offices and the other one is the "BIM implementation in Builders and Developers" (2016) developed by the Brazilian Chamber for the Construction Industry (CBIC, by its acronym in Portu-guese).

In addition, in May 2018, the Brazilian government passed Decree No. 9,377. Through this, the national BIM dissemination strategy was instituted, something that had been foreseen since the creation of CE-BIM in June 2017. Isolated initiatives by 
Brazilian state governments are also observed. Through the State Secretariat of Infrastructure and Logistics (Sinfra), Mato Grosso (MT) was the first Brazilian state to launch a bidding for 3D projects for highways requiring the use of BIM. In October 2017, Sinfra presented the bid notice for companies to execute $3,500 \mathrm{~km}$ of roads projects using the BIM platform.

The MT's initiative represented great advances, but Santa Catarina (SC) is the first Brazilian state to require the use of BIM for all public projects since 2018. Therefore, the "Caderno BIM" was published, a NBP that contains the procedures for project development following this methodology in SC.

Still in 2014, in the state of SC, the Technical Working Group for the implementation of BIM was also created and a technical cooperation agreement was signed with the Paraná Department of Infrastructure and Logistics to introduce BIM in both states. At the end of 2016, the state of Rio Grande do Sul also formalized an agreement with the SC to exchange experiences on technology (Steiner 2016).

Finally, in October 2018, the Government of Rio de Janeiro instituted the Building Information Modeling Dissemination Strategy, or BIM RJ Strategy, whose purpose is to provide a suitable environment for investment in BIM and to promote its diffusion in the state, in parallel to Decree No. 9377.

\section{RESEARCH METHOD}

Structured questionnaires were applied using the Google Docs tool from June to July 2018 in construction companies based in the Rio Grande do Norte and Paraíba, aiming to characterize the use of BIM in these Brazilian states. Figure 1 shows the flow chart of the questionnaire.

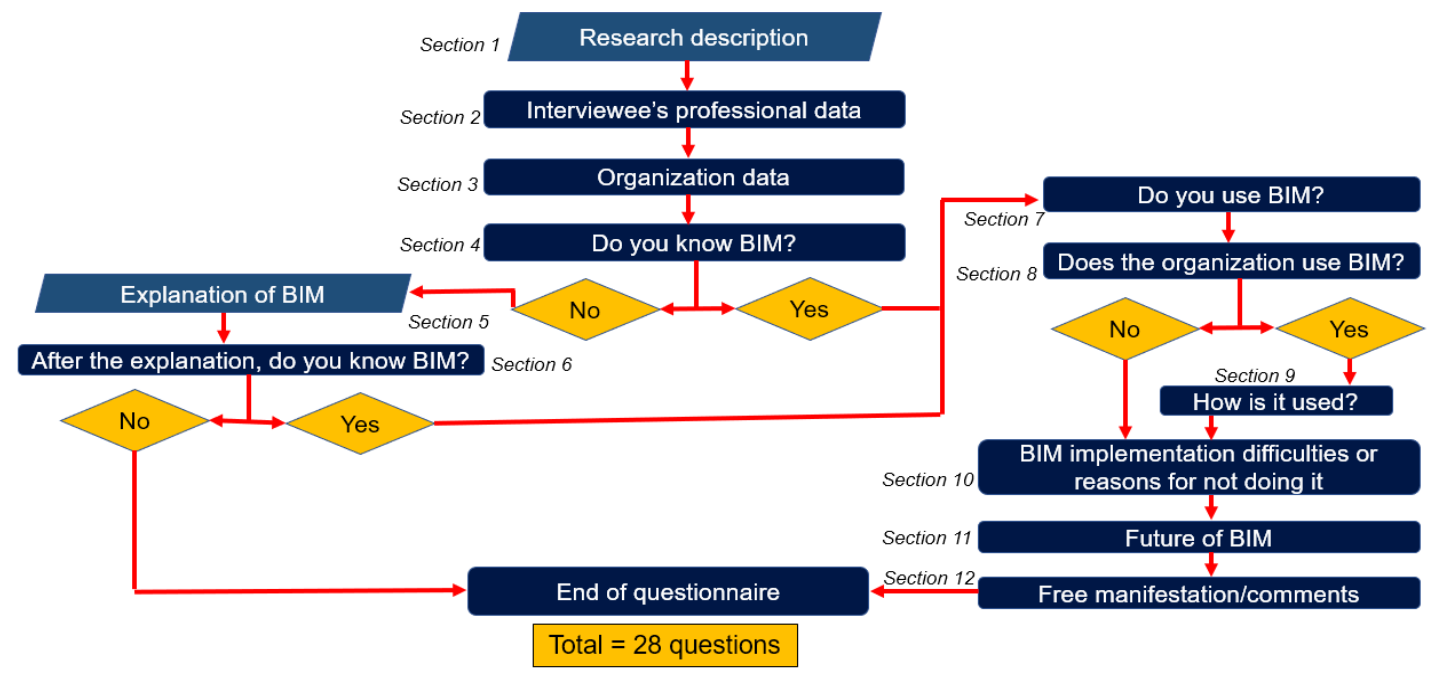

Figure 1: Questionnaire flow chart

The questionnaire is adapted from Carmona and Carvalho (2017), who investigated the adoption of BIM by sixteen of the main construction companies operating in the residential and commercial real estate market of the Distrito Federal state and the major difficulties faced during its implementation. It analyzes the interviewees' and companies profiles, the degree of the BIM uses, as well as the purpose of its application. Also, the major difficulties in its implementation or the reasons for not using it are questioned. In addition to modifying some questions from the original questionnaire, questions related to the recent period of economic recession in Brazil were added to this current study. 
In order to analyze the degree of adoption and to qualify the use of BIM in the states of Rio Grande do Norte and Paraíba, the structured questionnaire link was sent to companies operating in the local construction sector associated to the Construction Industry Syndicate (Sinduscon, by its acronym in Portuguese) of both states. Due to its ease of creation, survey responses and gratuity, the Google Forms platform was used to complete the questionnaire, which was sent in emails with a brief explanation about the survey.

Aiming to increase the number of answers and obtain impartial information, the questionnaires were designed to ensure that the respondent could not be identified while maintaining their privacy.

To ensure greater visibility of the survey by respondents and acquire a higher response rate, the Sinduscon of both states agreed to forward the survey link by their own institutional emails. While in Paraíba a high percentage of responses was acquired, in Rio Grande do Norte only a few companies collaborated with the survey.

The initial intention was for the questionnaires to be available online for two weeks, however, because the number of responses in the RN state was not satisfactory, the period was extended for another two weeks, accounting for one month. Due to this adversity, it was necessary to resubmit the questionnaire directly to company employees and request that they respond. As a result, the stipulated period for keeping the questionnaire online went from two weeks to one month between June and July 2018. This attempt to obtain more data for the analysis resulted in almost four times the responses initially acquired.

\section{RESULTS AND DISCUSSION}

Table 1 shows the number of companies affiliated with the Syndicates, the number of answered questionnaires and the percentage of that number represents over the total.

Table 1. - Percentual of answered questionnaires

\begin{tabular}{llll}
\hline \multirow{2}{*}{ Syndicate State } & $\begin{array}{l}\text { Affiliated } \\
\text { Companies }\end{array}$ & $\begin{array}{l}\text { Answered } \\
\text { Questionnaires }\end{array}$ & $\begin{array}{l}\text { Answering } \\
\text { Rate }\end{array}$ \\
\hline RN & 101 & 32 & $31,68 \%$ \\
PB & 168 & 38 & $22,62 \%$ \\
\hline
\end{tabular}

To analyze the answers, the questions were classified into the following seven points: professional profile, organization profile, knowledge of the term BIM (before and after explanation of the term), use of BIM and usage characterization, implementation difficulties and future projects for use of BIM.

\subsection{Professional profiles}

This parameter sought to analyze the position held by the professionals in the company, their education and experience in the field of construction. The answer to the position held was free and the classification adopted was between managerial and nonmanagerial occupations, according to Figure 2. 


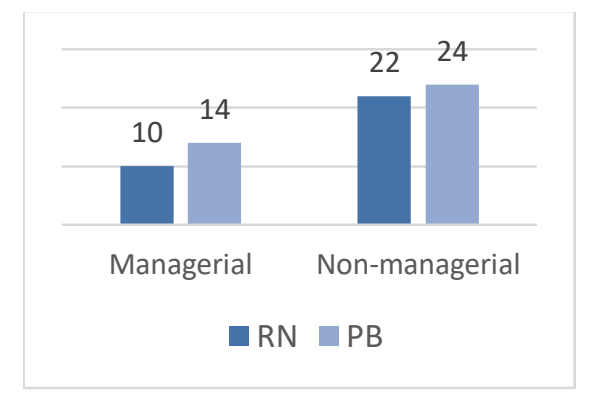

Figure 2: Positions held in the organization

According to Figures 3 and 4, most of the interviewees has a graduation in Civil Engineering and they are in the job market between 5 and 10 years (relatively short period) and occupy non-managerial jobs in their companies.

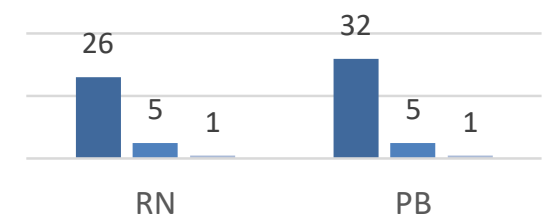

- Civil Engineering $\square$ Architecture

Others

Figure 1: Graduation area

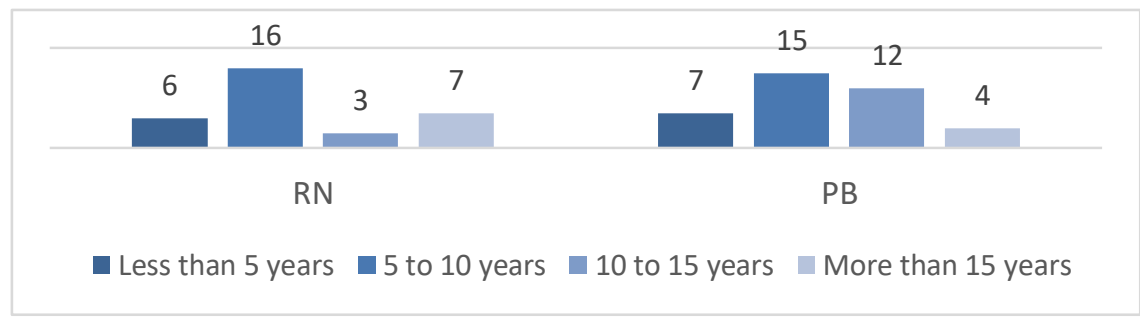

Figure 2: Professional experience (years)

\subsection{Organization profiles}

To draw the profile of the companies from Rio Grande do Norte and Paraiba, the questionnaire also sought to know the activities that they normally performed, in addition to the size and local scope of operation of the organization. As for the activities, the multiple-choice question with the possibility of more than one answer was used and the option to add an activity not mentioned was given. Figure 5 presents these results. 


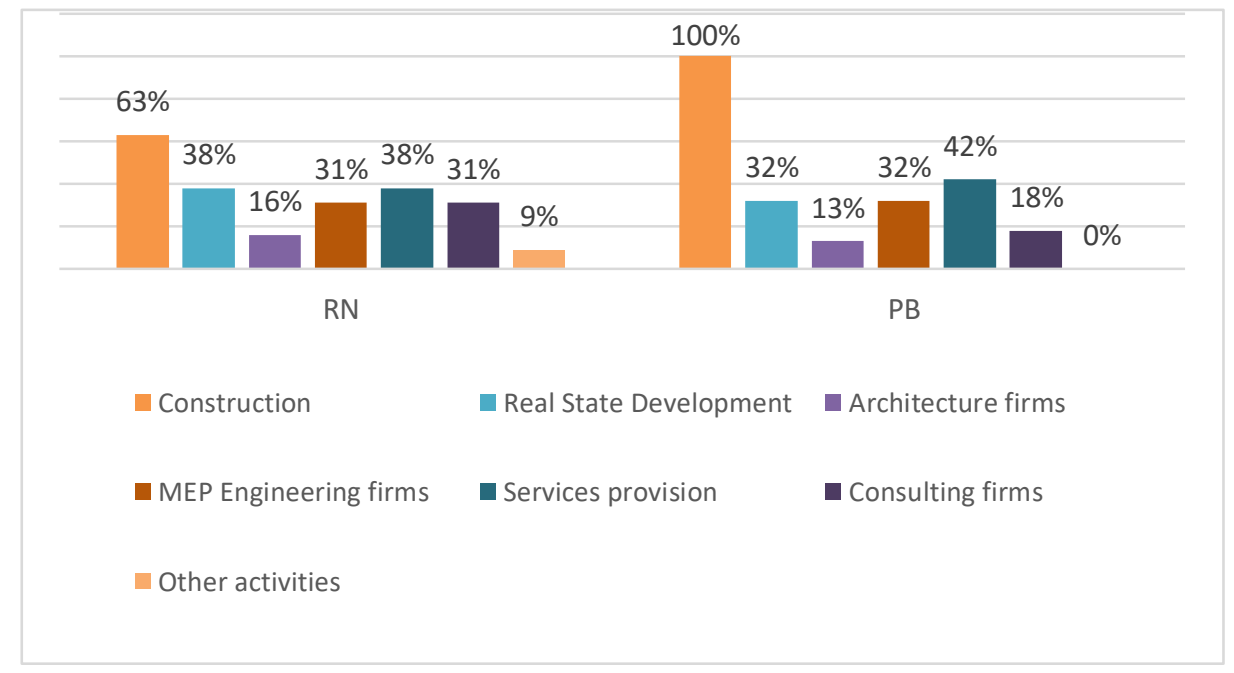

Figure 3: Activities performed by the companies

As for the size of the company, the analysis was made by the number of employees hired. It was considered a micro construction company with up to 19 employees; small construction company with 20 to 99 employees, medium construction company with 100 to 499 employees, and lastly large construction company with 500 or more employees. As shown in Figure 6, most companies classify themselves as micro or small.

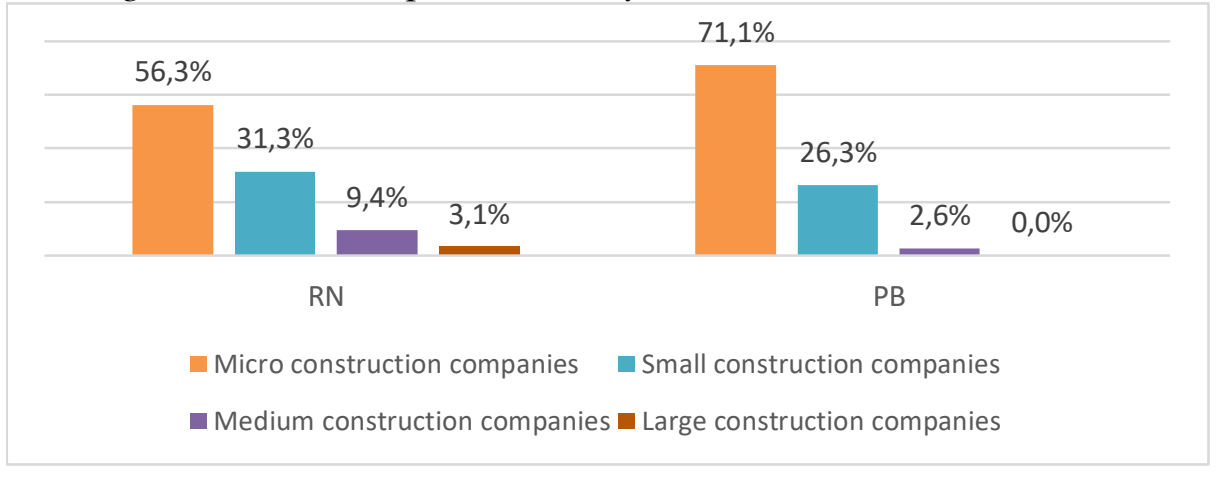

Figure 4: Companies size

Regarding the site operation of the companies, Figure 7 shows that a large part of their activities is local.

\begin{tabular}{|c|c|c|c|c|c|}
\hline \multirow[t]{2}{*}{$87,5 \%$} & \multicolumn{5}{|c|}{$78,9 \%$} \\
\hline & $12,5 \% \quad 0,0 \%$ & $0,0 \%$ & $21,1 \%$ & $0,0 \%$ & $0,0 \%$ \\
\hline \multicolumn{3}{|c|}{ RN } & \multicolumn{2}{|c|}{ PB } & \\
\hline \multicolumn{3}{|c|}{ - Local (state) } & & & \\
\hline \multicolumn{6}{|c|}{ Regional (Northeast states) } \\
\hline \multicolumn{6}{|c|}{ National (more than 10 states) } \\
\hline \multicolumn{6}{|c|}{ - International (actiong nationally and in other countries) } \\
\hline
\end{tabular}

Figure 5: Activity places of construction companies

Figure 8 presents the annual business revenue reported by respondents. The capital in about $60 \%$ of the companies don't reach US\$ 238.095,24. Considered the American dollar exchange of January 2020: US $\$ 1,00$ (dollar) = R $\$ 4,20$ (Brazilian real). 


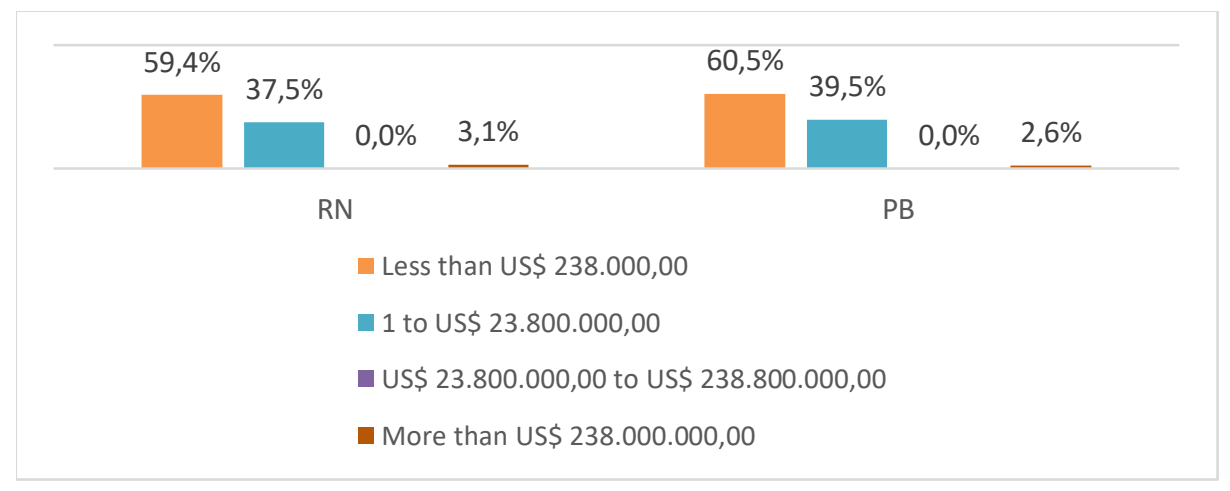

Figure 6: Business anual revenue

The Brazilian real estate market has lived through the last decade of great dynamism and has gone through two quite distinct phases. First, following the country's booming economic cycle, it experienced strong growth and registered the peak of prosperity. However, with the slowdown in the Brazilian economy starting in 2014, it entered a significant downward curve, which has caused construction sector to shrink dramatically.

According to Brazilian Institute of Geography and Statistics (IBGE) data, since the recession began in the second quarter of 2014, construction activity has shrunk by $21 \%$. In order to identify how much the companies were affected by the national economic crisis, questions were included in the questionnaire asking how many projects were in progress or under development in the period before and after this adversity. Figure 9 presents the level of damage to companies caused by the crisis. Only 3,1\% in RN claimed to have had no capital loss.

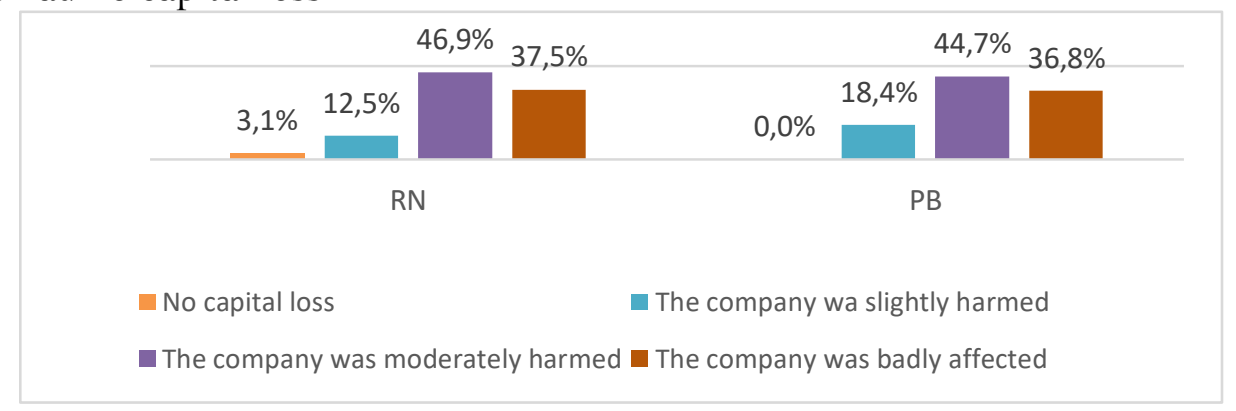

Figure 7: Intensity of injury caused by the economic crisis

\subsection{Knowledge on the BIM term}

The respondents were asked about their familiarity of the BIM term. For those who answered as not knowing what it means, the term was defined, and it was once again questioned if they understood it after the explanation. If they said "no", they would not be able to complete the questionnaire. Figure 10 expresses the first question; and after explanation to those who answered "no", $100 \%$ of them answered to be familiar in both states. 


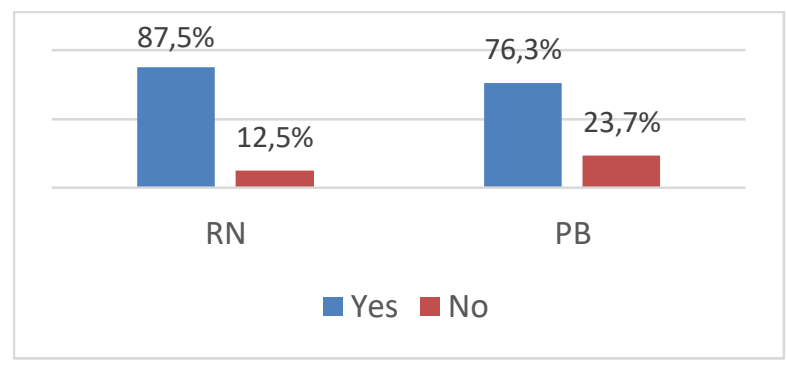

Figure 8: Familiarity with BIM term preceding explanation

After this procedure, it was investigated the professionals' personal positioning in relation to the BIM methodology through the multiple choice question exemplified in Figure 11. The companies of Rio Grande do Norte slightly stood out in relation to Paraíba both in the spontaneous question of familiarity with BIM and in the question of intent to use BIM and improvement in the near future (100\%).

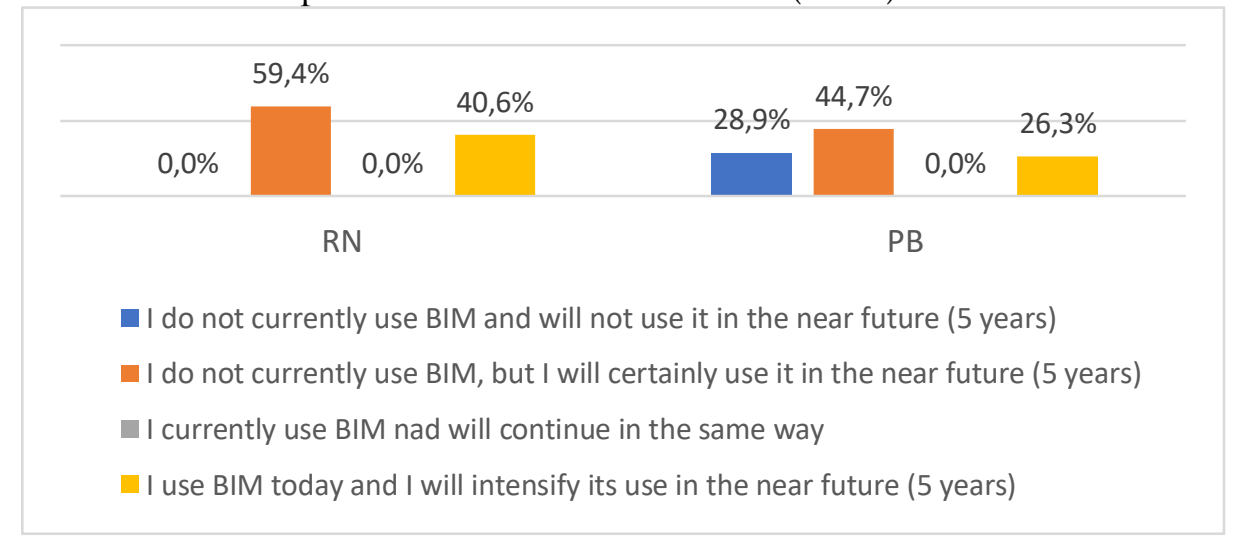

Figure 9: Personal positioning in relation to BIM

\subsection{Characterization of BIM utilization}

Then, the questionnaire sought to understand the implementation of BIM in companies, which is expressed in Figure 12. It shows that the negative answer is the majority in both states $(62,5 \%$ in $\mathrm{RN}$ and $73,7 \%$ in $\mathrm{PB})$.

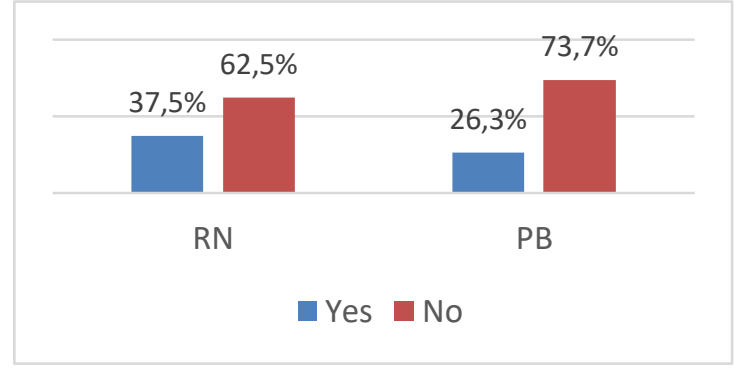

Figure 10: Companies using BIM

The BIM uses in companies that responded positively are present in Figure 13, establishing the 3D Modeling of Architecture and Project Compatibility as the main uses in Paraíba and Rio Grande do Norte.

Nine categories were presented (3D Architectural Modeling, 3D Structural Modeling, Collaborative Design on the same platform, Quantity Take-Off, Design Coordination, Clash Detection, 4D Modeling (Phase Planning), 5D Modeling, and 6D Modeling 
(Sustainability Analysis) with the possibility of more than one choice and insertion of a new category, but 3 of them (4D, 5D and 6D Modeling) received no answer.

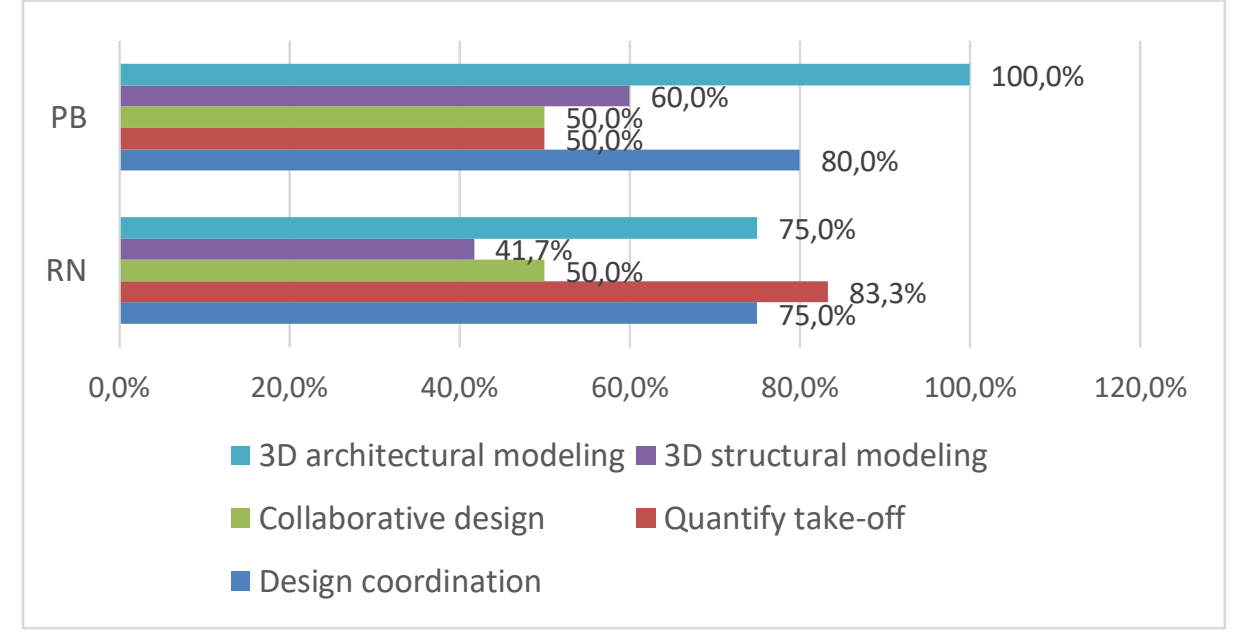

Figure 11: BIM activities used in organizations using BIM (percent)

Another question for those who already use BIM asks respondents to choose the statement that best approximates their reality, which best defines the way activities are performed. From the results shown in Figure 14, the only alternatives marked were A and $\mathrm{B}$, which means that all BIM activities are done within the organization itself in about the majority of companies in both states.

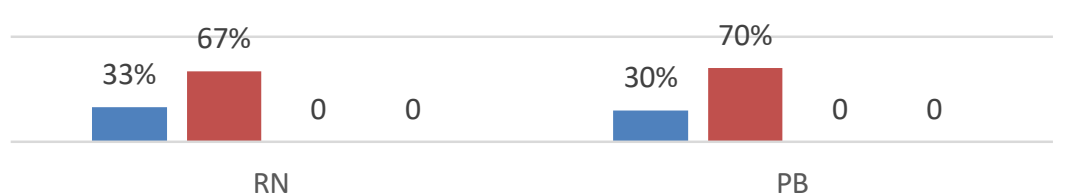

All BIM-related activities are internal. All involved are employees of the organization itself

- Part of the services are performed by outsourced companies, but control and management of processes involving BIM is the responsibility of the organization itself

- Part of the services are performed by outsourced companies. Process control and management involving BIM is the responsibility of an external consultant / expert, whose duties include the conversion of CAD

- All BIM processes are outsourced, the organization only benefits from BIM results

Figure 12: Characterization of BIM activities by companies

Moreover, Table 2 shows that most of these organizations ( $80 \%$ in $\mathrm{PB}$ and $83.3 \%$ in $\mathrm{RN}$ ) see positive or partially positive results in the implementation of BIM, although $20 \%$ and $17.6 \%$ have not perceived or measured any benefits.

Table 2. Results of BIM utilization

\begin{tabular}{lll}
\hline Results & RN & PB \\
\hline Positive & $58,3 \%$ & $50 \%$ \\
Partial & $25 \%$ & $30 \%$ \\
Not measured or perceived & $17,6 \%$ & $20 \%$ \\
\hline
\end{tabular}




\subsection{Difficulties in implementing BIM}

A series of questions was asked about the difficulties faced in adopting BIM for those who have already done so, or the reasons that prevent this process change from being made for those who have not yet done so. It was listed 9 topics considered in the literature as barriers, with an option to answer 0 to 3 , indicating none (0), little (1), much (2) and maximum (3) relevance. Results are presented in Table 3.

Table 3. - BIM implementation difficulties by level of importance (percentage)

\begin{tabular}{|c|c|c|c|c|c|c|c|c|}
\hline \multirow{2}{*}{ Difficulties } & \multicolumn{4}{|c|}{$\mathrm{RN}$} & \multicolumn{4}{|c|}{$\mathrm{PB}$} \\
\hline & 0 & 1 & 2 & 3 & 0 & 1 & 2 & 3 \\
\hline $\begin{array}{l}\text { Ignorance/lack of information about } \\
\text { BIM }\end{array}$ & 12,5 & 25,0 & 37,5 & 25,0 & 18,8 & 42,1 & 28,9 & 10,5 \\
\hline $\begin{array}{l}\text { Little importance given to BIM by } \\
\text { organization and/or project leaders }\end{array}$ & 5,6 & 18,8 & 37,5 & 28,1 & 21,1 & 36,8 & 39,5 & 2,6 \\
\hline $\begin{array}{l}\text { Lack of specialized internal } \\
\text { (organization) labor }\end{array}$ & 9,4 & 12,5 & 34,4 & 43,8 & 5,3 & 23,7 & 34,2 & 36,8 \\
\hline Software complexity & 25,0 & 31,3 & 34,4 & 9,4 & 18,9 & 29,7 & 40,5 & 10,8 \\
\hline The value of software licenses & 12,9 & 6,5 & 35,5 & 45,4 & 5,3 & 5,3 & 36,8 & 52,6 \\
\hline The cost of the IT infrastructure & 18,8 & 18,8 & 34,4 & 28,1 & 7,9 & 28,9 & 44,7 & 18,4 \\
\hline BIM is not required for the market & 18,8 & 34,4 & 21,9 & 25,0 & 23,7 & 31,6 & 26,3 & 18,4 \\
\hline $\begin{array}{l}\text { External designers that the } \\
\text { organization works with don't use } \\
\text { BIM }\end{array}$ & 9,4 & 9,4 & 31,1 & 50,0 & 7,9 & 5,3 & 26,3 & 60,5 \\
\hline $\begin{array}{l}\text { Difficulty in coordinating the } \\
\text { various project fronts and steps } \\
\text { involved }\end{array}$ & 25,0 & 15,6 & 31,3 & 28,1 & 26,3 & 39,5 & 26,3 & 7,9 \\
\hline
\end{tabular}

For both states, the most critical aspect is that external designers do not use BIM. For this, option 3 was selected by $50 \%$ in the $\mathrm{RN}$ and $60.5 \%$ in the PB.

In $\mathrm{RN}$, the factors that were considered having the most relevance are the cost of software licenses $(81.3 \%)$, external designers with whom the company works use BIM $(81.3 \%)$, lack of skilled internal labor $(78.2 \%)$, lack of knowledge or little importance given to BIM by organization leaders $(65.6 \%)$ and cost of necessary IT infrastructure $(62.5 \%)$.

In $\mathrm{PB}$, the points considered most critical were similar to those of RN'n, except for the lack of knowledge or little importance given to BIM by the organization's leaders. Apart from that, the highlight was the value of software licenses (89.4\%), external designers with whom the company works do not use BIM (86.8\%), lack of specialized internal labor (71\%) and cost of IT infrastructure required (63.1\%). 


\subsection{The BIM future}

The last questionnaire section was about the BIM future. Firstly, it was asked if the respondents believe if BIM will ever replace CAD. Results are shown in Figure 15. Only in Paraíba there is no expectation of this change occurring.

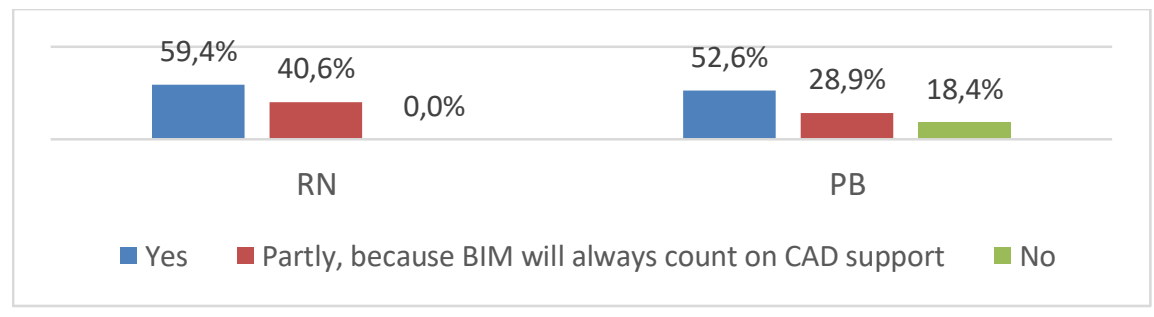

Figure 13: Thoughts on replacing CAD with BIM

Finally, it was asked about the approximate period for a possible standardization of BIM in the market. Figure 16 shows the answers obtained on this question.

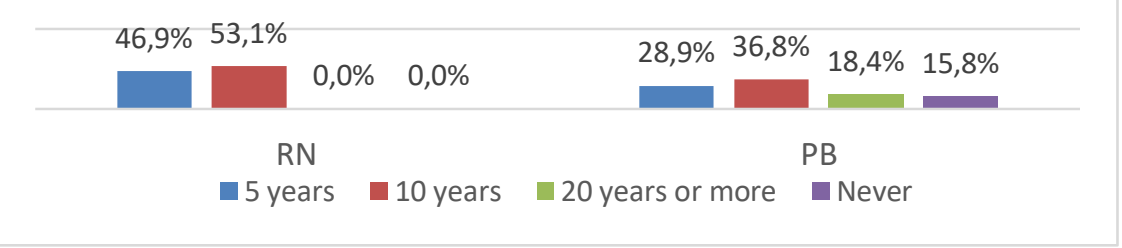

Figure 14: Expectation on BIM becoming industry standard

While in PB $15.8 \%$ of the companies believe that BIM will never become standard in the market, the state of RN stood out in highlighting a maximum period of 10 years. This may reveal more favorable trends for the use of BIM in this state.

\subsection{Free manifestation of respondents}

Concluding the questionnaire, respondents could comment on anything they thought relevant to the BIM discussion. No comments were made by $\mathrm{PB}$, but ten people from RN spoke about it.

One professional reported that he has studied and used BIM since college and has also been a fellow in a BIM implementation program at the Infrastructure Superintendence of the Federal University of Rio Grande do Norte (UFRN) and a teaching assistant in the BIM course at UFRN (2010-2012). However, when he graduated, he experienced a lot of difficulty, especially since none of the structural and MEP designers he worked with use or even know about BIM. In his professional experiences, he developed an Architecture BIM Model, and then it was necessary to export to CAD for the development of MEP designs, making the design process considerably more laborious.

A second professional reported the similar frustration that many local companies already use the BIM platform, but end up regressing by having to export to CAD to collaborate with another professional or company responsible for the continuity of the design.

Many comments drew attention to the need to raise awareness of the importance of BIM, through the opening of more courses and training that can train professionals, and lectures that address the theme.

It was also mentioned that public agencies should give preference to designs made in BIM platform, due to their transparency and reduction of errors, resulting in more 
reliability in construction. For another person, the encouragement of the Federal Government through the BIM Dissemination Strategy is already influencing the market, as professionals are already more curious and willing to face the required procedural change.

\section{CONCLUSIONS}

The major contribution of this study is the characterization of the use of BIM in the states of Rio Grande do Norte and Paraíba, both states of the Brazilian northeast region, which was not covered in previous studies. Even through positive outcomes, BIM use is not a majority in both of them and it faces a number of obstacles, such as the cost of technology, lack of skilled labor, or issues of personal interest by Architecture, Engineering and Construction industry.

If the regional analysis performed is conducted in multiple locations, it will allow the understanding of difficulties and particularities of BIM implementation in a more detailed way, which may contribute to its dissemination in Brazil. From these results, specific guidelines can be developed to address the difficulties encountered in each location.

This study presented as limitation the analysis of only two of the nine Northeastern Brazilian states. Future research could apply the questionnaire in other states, aiming to obtain more consistent data of this region, as it is also recommended to be conducted for other Brazilian regions. Consequently, parameters can be created to determine the precise level of macro adoption and maturity of BIM in Brazil.

It is noteworthy that the results obtained can generate numerous surveys, since the comparison between the various regions, or even neighboring states, which may present quite different realities. Moreover, questions can be explored individually. For example, as the questionnaire addressed the economic downturn, it is possible to investigate how much it has influenced the implementation of BIM, as some companies may have taken advantage of the reduced workload for training and capacity building or introduced technologies that optimize their processes.

\section{REFERENCES}

Carmona, F., and Carvalho, M. (2017). Caracterização da utilização do BIM no Distrito Federal. Ambiente Construído, 17(4), pp. 385-401.

Eastman, C., Teicholz, P., Sacks, R. and Liton, K. (2008). BIM Handbook: a guide to building information modeling for owners, managers, designers, engineers, and contractors. New Jersey: John Wiley \& Sons, p. 490.

Farias, D., Barros, M. and Santos, M. (2016). Proposição de um protocolo para contratação de projetos em BIM para o mercado da construção civil nacional. In: XV Encontro Nacional de Tecnologia do Ambiente Construído, ENTAC. pp.4774-4784.

Jones, S., and Bernstein, H. (2014). The Business Value of BIM for Construction in Major Global Markets: How Contractors Around the World Are Driving Innovation With Building Information Modeling. MCGRAW-HILL CONSTRUCTION SMARTMARKET REPORT. Bedford: Copyright, 2014.

Kassem, M., Succar, B. and Dawood, N. (2015). Building Information Modeling: Analyzing Noteworthy Publications of Eight Countries Using a Knowledge Content Taxonomy. Building Information Modeling, pp.329-371.

Pini (2013). Uso Do BIM. [online] Available at: <http://piniweb.pini.com.br> 
Smith, P. (2014). BIM implementation - global strategies. Procedia Engineering, 85, pp. 482-492.

Steiner, L. (2016). Análise Da Implementação Da Plataforma BIM No Setor Da AEC Do Estado De Santa Catarina. Graduation. South of Santa Catarina University.

Succar, B. (2009). Building information modelling framework: A research and delivery foundation for industry stakeholders. Automation in Construction, 18(3), pp.357-375. 